\title{
Simulation Analysis of the Orientation Ability for Galileo in Asia-pacific Region
}

\author{
L.L. Cui, Y.L. Lu, M. Liao \\ School of Urban and Rural Construction \\ Chengdu University \\ Sichuan, China
}

\begin{abstract}
On the base of satellites' circulate rule, Galileo system simulation software is exploited and operated in the paper. The capability of Galileo navigation and positioning is analyzed and validated thought positioning precision in five different areas is computed. These demonstrates dear know about good capability of positioning all over the world.
\end{abstract}

Keywords-galileo positioning system; navigation; positioning; simulation

\section{INTRODUCTION}

With the acceleration of European's Galileo system network, the world will have four satellite systems coexistence. The scholars had a large nu mber of simulation study about the influencing factors of Galileo navigation and positioning and the combination of Global Positioning System (GPS), BDS and Galileo's.

In this paper, there is the simulation and analysis of Galileo positioning accuracy in different latitude regions in the Asia-pacific region, thus it can preliminary argued the positioning performance of this system in the Asia-pacific region.

\section{SATELLITE CONSTELLATION SIMULATION PRINCIPLES}

The simulation purpose was to get the satellite 3D coordinate of the fixed coordinate system. According to the Kepler's theorem, if the Kepler's six parameters are known, the satellite coordinates in the orbit coordinate system can be got. The mathematical models are as follow:

$$
\left[\begin{array}{l}
\xi_{s} \\
\eta_{s} \\
\zeta_{s}
\end{array}\right]=a_{s}\left[\begin{array}{l}
\left(\cos E_{s}-e_{s}\right) \\
\left(1-e_{s}^{2}\right)^{1 / 2} \sin E_{s} \\
0
\end{array}\right]
$$

$\left(\xi_{s}, \eta_{s}, \zeta_{s}\right)$ in the formula is the satellite coordinates in the orbit coordinate system, $a_{s}$ is the semi-major axis of orbit, $e_{s}$ is the orbital eccentricity, $\mathrm{E}_{\mathrm{s}}$ is as the eccentric anomaly, $M_{s}$ is the flat anomaly in a moment calculated by the next formula:

$$
\begin{gathered}
E_{s}=M_{s}+e_{s} \sin E_{s} \\
E_{s}=M_{s}+\left(180^{\circ} / \pi\right) e \sin E_{s} \\
M_{s}=n \times\left(t-t_{0}\right)
\end{gathered}
$$

Here, $t_{0}$ is the simulation start time, $t$ is observation time, and $n$ is the average angular velocity for satellite movement. The mathematics transformation model to the satellite coordinate transformation for the solid coordinate is:

$$
\left[\begin{array}{l}
X \\
Y \\
Z
\end{array}\right]=R_{3}(G A S T) R_{3}(-\Omega) R_{1}(-i) R_{3}\left(-\omega_{S}\right)\left[\begin{array}{c}
\xi_{S} \\
\eta_{S} \\
\zeta_{S}
\end{array}\right]
$$

Among them,

$$
\begin{gathered}
\mathrm{R}_{3}(-\Omega)=\left(\begin{array}{ccc}
\cos \Omega & -\sin \Omega & 0 \\
\sin \Omega & \cos \Omega & 0 \\
0 & 0 & 1
\end{array}\right) \\
\mathrm{R}_{1}(-\mathrm{i})=\left(\begin{array}{ccc}
1 & 0 & 0 \\
0 & \operatorname{cosi} & -\sin \mathrm{i} \\
0 & \sin \mathrm{i} & \operatorname{cosi}
\end{array}\right) \\
\mathrm{R}_{3}\left(-\omega_{5}\right)=\left(\begin{array}{ccc}
\cos \omega_{\mathrm{s}} & -\sin \omega_{\mathrm{s}} & 0 \\
\sin \omega_{s} & \cos \omega_{s} & 0 \\
0 & 0 & 1
\end{array}\right), R_{3}\left(\text { GAST) }=\left[\begin{array}{ccc}
\cos (G A S T) & \sin (G A S T) & 0 \\
-\sin (G A S T) & \cos (G A S T) & 0 \\
0 & 0 & 0
\end{array}\right]\right.
\end{gathered}
$$

Among them, $\Omega$ is ascending node in red, $i$ is the orbital inclination, and $\omega_{s}$ is perigee angular distance, GAST is Greenwich sidereal time for vernal equinox. As a result, we get the satellite $3 \mathrm{D}$ coordinates under the ground fixed coordinate system.

\section{SIMULATION AND ANALYSIS}

In the process, it was assumed that the initial epoch observation is on April 30, 2014 (GTS time), there are three circular orbits, nine satellites distributed uniform each orbit and the flat anomaly of the starting time $\left(t_{0}=0\right.$ ) of each first satellite. The basic parameters of simulation track are: semi-major axis $\alpha$ is $2993.707 \mathrm{~km}$, orbital inclination $i$ is $56^{\circ}$, orbital eccentricity $e_{s}$ is 0 , Perigee angular distance $\omega_{\text {is }} 0$, scending node in red $\Omega$ is respectively $60^{\circ}, 180^{\circ}$, $300^{\circ}$, flat anomaly $M_{s}$ is $0^{\circ}$ (the flat anomaly of the starting time $\left(t_{0}=0\right.$ ) of each first satellite).

The city where the five representative to locate the simulation calculation had been chose in this paper. See the table below. 
TABLE I. THE SIMULATION CITY LIST.

\begin{tabular}{|c|c|c|c|}
\hline Area & City & Latitude E & Longitude N \\
\hline Russia & Yakutsk & $129^{\circ} 51^{\prime}$ & $62^{\circ} 01^{\prime}$ \\
\hline Mongolia & Ulan Bat or & $106^{\circ} 55^{\prime}$ & $47^{\circ} 58^{\prime}$ \\
\hline China & Chengdu & $104^{\circ} 04^{\prime}$ & $30^{\circ} 40^{\prime}$ \\
\hline China & Hong Kong & $114^{\circ} 06^{\prime}$ & $22^{\circ} 12^{\prime}$ \\
\hline Malay sia & Kuala Lumpur & $101^{\circ} 41^{\prime}$ & $3^{\circ} 08^{\prime}$ \\
\hline
\end{tabular}

\section{A. Satellite Visible for Analysis}

1) according to the principle of space geometry, $\left(\frac{2 \times X_{k}^{0}}{a^{2}}, \frac{2 \times Y_{k}^{0}}{b^{2}}, \frac{2 \times Z_{k}^{0}}{c^{2}}\right)$

is the tangent plane normal vector of receiver position as the point of tangency and tangent to the earth ellipsoid. Among them, $\left(X_{k}^{0}, Y_{k}^{0}, Z_{k}^{0}\right)$ is the 3D coordinates of receiver in the ground fixed coordinate; $a, b, c$ is the parameters of ellipsoid $\frac{x^{2}}{a^{2}}+\frac{y^{2}}{b^{2}}+\frac{z^{2}}{c^{2}}=1$, and $b=c$.

2) $\left(X^{j}-X_{k}^{0}, Y^{j}-Y_{k}^{0}, Z^{j}-Z_{k}^{0}\right)$ is the direction vector computed of satellite and receiver. Among them, $\left(X^{j}, Y^{j}, Z^{j}\right)$ is the $3 \mathrm{D}$ coordinates of satellite in the ground fixed coordinate;

3) The angle between the direction and the above normal vector is computed. Because the receiver can only receive the satellite signal that angle is greater than 15 degree, so the angle must be less than 75 degree.

According to the above principle, we had got the satellite visible situation of these five cities in one day as shown in Tab. 3.

TABLE II. THE ANAL YSIS OF VISIBLE SATELLITE NUMBER OF CITIES (\%).

\begin{tabular}{|c|c|c|c|c|c|}
\hline \multirow{2}{*}{ Area } & \multirow{2}{*}{ City } & \multicolumn{4}{|c|}{ Visible satellite number } \\
\cline { 3 - 6 } & & 6 & 7 & 8 & 9 \\
\hline Russia & Yakutsk & $6 \%$ & $78 \%$ & $16 \%$ & $0 \%$ \\
\hline Mongolia & Ulan Bat or & $78 \%$ & $22 \%$ & $0 \%$ & $0 \%$ \\
\hline Sichuan, China & Chengdu & $49 \%$ & $35 \%$ & $16 \%$ & $0 \%$ \\
\hline $\begin{array}{c}\text { Hong Kong special } \\
\text { administrat ive region }\end{array}$ & Hong Kong & $0 \%$ & $30 \%$ & $66 \%$ & $4 \%$ \\
\hline Malaysia & $\begin{array}{c}\text { Kuala } \\
\text { Lumpur }\end{array}$ & $0 \%$ & $0 \%$ & $60 \%$ & $40 \%$ \\
\hline
\end{tabular}

From Tab. 3, the number of satellites in low latitudes than in high latitudes and mid-latitude regions, especially most number in equatorial regions. And there are the same distributions of high and middle latitude regions.

\section{B. PDOP Analysis}

The basic principle formula of satellite positioning is

$$
\mathrm{R}_{k}^{j}=\sqrt{\left(X^{j}-X_{k}^{0}\right)^{2}+\left(Y^{j}-Y_{k}^{0}\right)^{2}+\left(Z^{j}-Z_{k}^{0}\right)^{2}}
$$

$R_{k}^{j}$

$k$ is the distance between the satellite and receiver $\mathrm{k}$ in $\mathrm{j}$ moment. Based on least squares principle, the power inverse matrix could be got from eq. 5 .

$$
Q_{x x}=\left(A^{T} A\right)^{-1}=\left[\begin{array}{llll}
Q_{11} & Q_{12} & Q_{13} & Q_{14} \\
Q_{21} & Q_{22} & Q_{23} & Q_{24} \\
Q_{31} & Q_{32} & Q_{33} & Q_{34} \\
Q_{41} & Q_{42} & Q_{43} & Q_{44}
\end{array}\right]
$$

So PDOP was got:

$$
P D O P=\sqrt{Q_{11}+Q_{22}+Q_{33}}
$$

According to the above formula, PDOP value distribution of each city in a day is shown in Fig. 1.

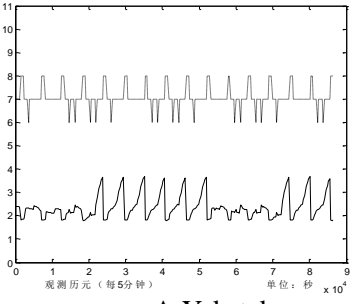

A.Yakutsk

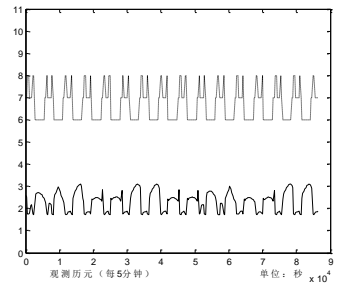

C. Chengdu

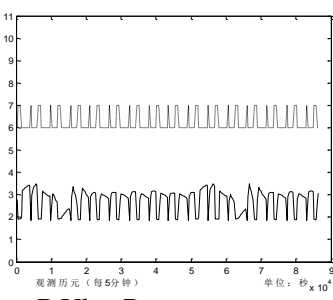

B.Ulan Bator

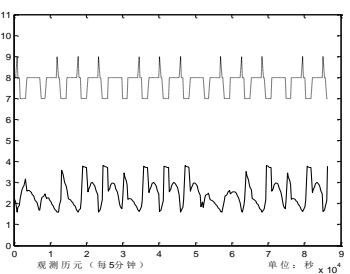

D. Hong Kong

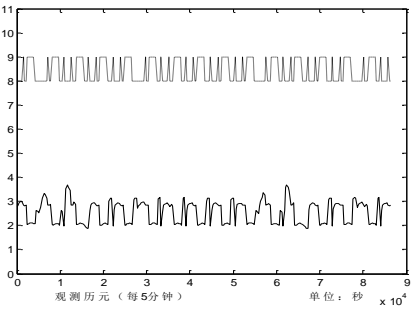

E. Kuala Lumpur

FIGURE I. THE PDOP VALUE DISTRIBUTION IN ONE DAY IN GIVEN AREAS (NOTE: SOLID LINE REPRESENTS PDOP, DOTTED LINE REPRESENTS NUMBER OF SATELLITE OF IN SOME MOMENT)

From Fig. 1, we can see the PDOP value distribution of the different areas in one day is roughly the same. PDOP value is about 2.0. It indicates that Galileo system in Asia-pacific region has a great navigation and positioning performance.

\section{CONCLUSIONS}

Through the simulation comparison of Galileo system, we find that Galileo system has a great positioning performance. But now Galileo system is as sembling, many problems which need be studied will be verified after the system built.

\section{ACKNOWLEDGEMENT S}

Supported by Youth Foundation of Chengdu University (Item no: 2014XJZ22) and the scientific research booster program of Urban and rural construction college.

\section{REFERENCES}

[1] Chen Xiuwan, Fang Yu, Yin Jun, Zhang Huaiqing, Galileo navigation positioning system, Beijing: Beijing University, 2005

[2] Wang Zemin, Luan Jingbin, Galileo satellite positioning system phase combination observation model research, Geomatics and Information Science of Wuhan University, 2003, 28(6),723-727 
[3] Cui Lilu, He Xiufeng, Luo Zhicai, Liu Zhiping Simulation analysis of orientation ability for Galileo system, Journal of Geomatics, 32(4), pp 10-12, 2007

[4] Cui Lilu, Luo Zhicai, Zhong Bo, Wang Haihong Effects of Observation Noise to the Data Fusion Results by Frequency Domain Input-Output Method, Journal of Geodesy and Geodynamics, 29(4), pp 79-82, 2009

[5] Cui Lilu the interpolation algorithm research on the gravity satellite acceleration data, Engineering of Surveying and Mapping, 21(3), pp 21-26, 2012

[6] Aron Pinker. European GNSS--Competitive, yet Cooperative [J]. GPS Solutions, 1999, 3(2), 28-39

[7] Christian Tiberius, Thomas Pany, Bernd Eissfeller, Peter Joosten and Sandra Verhagen 0.99999999 confidence ambiguity resolution with GPS and Galileo[J].GPS Solutions,2002,6(1-2), 96-99 